\title{
Investigation of Hemogram, Endoscopy, Demographic Properties of Patients Applied by Fecal Occult Blood Test Screening
}

\author{
Özlem Özdemir ${ }^{1}$, Çağrı Akalın², Hamza Çınar ${ }^{3}$ \\ ${ }^{1}$ Internal Medicine, Medicine Faculty, University Ordu, Turkey \\ ${ }^{2}$ Ordu Training and Research Hospital, Department of General Surgery, Ordu, Turkey \\ ${ }^{3}$ General Surgery, Medicine Faculty, University Ordu, Turkey
}

Received: 28 March 2019, Accepted 24 September 2019, Published online: 31 December 2019

(C) Ordu University Institute of Health Sciences, Turkey, 2019

\begin{abstract}
Objective: Colorectal cancer (CRC) is one of the most common cancers in the world. Fecal occult blood test (FOBT) is easy and commonly used test to its screening. The aim of this study was to investigate the demographic characteristics, hemogram results and endoscopy and outcome status of the patients who underwent FOBT on history and clinical suspicion and to contribute to the literature.

Methods: 400 patients who were admitted to the general surgery polyclinic between 01/12/2016 and 12/12/2017 in Ordu University Medical Faculty Training and Research Hospital were evaluated retrospectively. The data of 349 patients who underwent FOBT was reached. Age and sex, hemoglobin, hematocrit, ferritin levels, upper and lower gastrointestinal endoscopy results and pathology results of endoscopic biopsies were recorded.

Results: 38 (10.9\%) with FOBT (+) and 311 (89.1\%) with FOBT (-) of 349 patients were detected. There was no statistically significant difference between the two groups in terms of the average age $(p=0.27)$ and gender $(p=0.26)$. There was a significant difference between the two groups in terms of the rate of upper gastrointestinal endoscopy $(\mathrm{p}=0.03)$. There was a significant difference between the two groups in terms of the rate of colonoscopy $(\mathrm{p}=0.001)$. Malignancy was detected in $22,2 \%$ of FOBT $(+)$ and in $1,63 \%$ of FOBT (-) group by colonoscopy. There was a statistically significant difference between the two groups in terms of disease diagnoses $(\mathrm{p}=0.001)$. There was no statistically significant difference between the two groups in terms of Helicobacter Pylori $($ H. pylori $)(\mathrm{p}=0.31)$ and intestinal metaplasia $(\mathrm{p}=0.44)$. There was a statistically significant difference between the two groups in terms of $\mathrm{Hb}$ and Htc value $(\mathrm{p}=0.05)$.

Conclusion: According to the results of FOBT, the application of endoscopy to the patients who are required, provide to detect the precancerous lesions as well as the malignancies of the upper and lower gastrointestinal tract. Good knowledge of the importance of this test will allow early detection of malignancy.

Keywords: Fecal occult blood test, Colorectal cancer, Endoscopy
\end{abstract}

Suggested Citation: Ozdemir O, Akalın C, Cinar H. Investigation of Hemogram, Endoscopy, Demographic Properties of Patients Applied by Fecal Occult Blood Test Screening. Middle Black Sea Journal of Health Science, 2019; 5(3): 180-185

Address for correspondence/reprints:

Özlem Özdemir
E-mail: ozlemtfl@hotmail.com

DOI: $10.19127 / \mathrm{mbsjohs.531631}$ 


\section{Introduction}

Fecal occult blood test (FOBT) is a current screening method for the colorectal cancer (CRC). It is based on the concept of detecting blood by the vascularized lesion (Carroll et al., 2014). Colorectal cancer is the third most common cancer in men and the second most common cancer in women worldwide (Torre et al., 2012). Therefore, screening and examination decision is important in early detection of suspected patients. FOBT is available, cheap and noninvasive test. On the other hand, anemia in peptic ulcer and gastric cancer may also be a sign of chronic bleeding, and in this respect, this test is a guide. Helicobacter Pylori (Hp) is the most common cause of many gastrointestinal diseases. More than half of the world's population is infected with $\mathrm{Hp}$ (Eusebi et al., 2014). İt is involved in the etiology of many gastrointestinal diseases as gastritis, peptic ulcer, functional dyspepsia, stubborn iron deficiency anemia, gastric mucosaassociated lymphoma (maltoma) and gastric adenocarcinoma (Lee et al.,2016; Bae et al., 2018; Adamu et al., 2010). In gastrointestinal system (GIS) diseases, simple complaints such as dyspepsia may be due to benign reasons such as Helicobacter Pylori and gastritis, yet dyspepsia, weight loss, secret or overt gastrointestinal bleeding may indicate a serious condition such as a gastric or colorectal malignancy (Ioannou et al., 2002). Symptom-based models have limitations, as they may present only at an advanced stage of the illness; furthermore, patients may ignore or not report symptoms. Therefore, only symptom-based examination and diagnosis are not sufficient. In this study, we aimed to investigate the demographic characteristics, hemoglobin, hematocrit, ferritin levels, Helicobacter Pylori existance, endoscopy and endoscopic pathology results in patients who underwent the FOBT on history and clinical suspicion.

\section{Methods}

A total of 400 patients who were admitted to the general surgery polyclinic between 01/12/2016 and $12 / 12 / 2017$ in Ordu University Medical Faculty Training and Research Hospital were evaluated retrospectively. The data of 349 patients who underwent FOBT was reached. Age and sex, hemoglobin, hematocrit, ferritin levels, upper and lower GIS endoscopy results and pathology results of endoscopic biopsies were recorded. Detection of the fecal occult blood is made by the fecal immunohistochemical testing. Hemogram parameters were measured by Sysmex XN 1000 device. According to the World Health Organization Guidelines, the hemoglobin level below of $12 \mathrm{~g} / \mathrm{dl}$ in women and below of $13 \mathrm{~g} / \mathrm{dl}$ in men, the hematocrit level below of $36 \%$ in women and below of $39 \%$ in men, the serum ferritin level below of $50 \mathrm{mg} / \mathrm{L}$ and serum vitamin B12 level below of $200 \mathrm{pg} / \mathrm{ml}$ for both sexes were considered as low. Endoscopies of the patients were performed by the same specialist and biopsy specimens were evaluated by the same pathologist. Pathology specimens were stained with hematoxylin-eosin and modified giemsa method and examined by light microscopy.

The study was approved by Ordu University Ethics Committee.

\section{Statistical Analysis:}

İn our study, descriptive statistics were expressed as mean, standard deviation, minimum and maximum values for continuous variables and were expressed as numbers and percentages for categorical variables. Mann Whitney U test was performed for continuous variables. Chi-square test was used to determine the relationship between categorical variables. The statistical significance level was taken as $5 \%(\mathrm{p}=0.05)$ and the statistical package program (SPSS) was used for the calculations.

\section{Results}

The study included 349 patients which in 38 $(10.9 \%)$ with FOBT (+) and $311(89.1 \%)$ with FOBT (-). The mean age of the patients was 55.50 $\pm 14.74(\min 18-\max 88)$. The mean age was 58.89 \pm 12.89 (min 39-max 87) in FOBT (+) group and the mean age was $55.08 \pm 14.99(\min 19-\max 88)$ in FOBT (-) group. There was no statistically significant difference between the two groups in terms of the average age $(p=0.27)$.

Of the 349 patients, $239(68.5 \%)$ were female and $110(31.5 \%)$ were male. İn FOBT $(+)$ group 23 $(60.5 \%)$ were female and $15(39.5 \%)$ were male. İn FOBT (-) group $216(69.5 \%)$ were female and 95 $(30.5 \%)$ were male. There was no significant difference between the two groups in terms of gender $(\mathrm{p}=0.26)$.

The mean $\mathrm{Hb}$ value of the patients was $13.24 \pm$ $1.78(8.2-17.2) \mathrm{mg} / \mathrm{dl}$. The mean $\mathrm{Hb}$ value was found to be $13.35 \pm 1.84(8.2-17.2) \mathrm{mg} / \mathrm{dl}$ in the FOBT (-) group and $12.35 \pm 0.78(11.1-13.2) \mathrm{mg} / \mathrm{dl}$ in FOBT $(+)$ group. There was a statistically significant difference between the two groups in 
terms of $\mathrm{Hb}$ value $(\mathrm{p}<0.05)$. The mean $\mathrm{Htc}$ value was $\% 40,24 \pm 4.72$ (27.6-51.7). The mean Htc value was found to be $\% 40.18 \pm 4.96(27.76-51.7)$ in the FOBT (-) group and \% $38.16 \pm 2.74(33.5-45.4)$ in FOBT (+) group. There was a statistically significant difference between the two groups in terms of Htc value ( $\mathrm{p}<0.05$ ).

When the patients were examined for anemia; it was detected in 49 (20.5\%) female and $47(42.7 \%)$ male patients. There was a statistically significant difference between two sexes in terms of anemia ( $p$ $<0.001)$. Anemia was detected in $14(36.8 \%)$ patients with (+) FOBT and in $82(26.4 \%)$ patients with (-) FOBT. There was no statistically significant difference between the two groups in terms of anemia $(\mathrm{p}=0.17)$. The mean ferritin value of the patients was $78.22 \pm 74.85(3.10-503) \mathrm{mg} / \mathrm{L}$. There was no statistically significant difference between the groups in term of ferritin values ( $p>0.05)$.

Helicobacter Pylori was detected in 3 patients of FOBT (+) in 15 patients of FOBT (-) group. There was no statistically significant difference between the two groups in terms of $H$. pylori presence $(\mathrm{p}=$ 0.31 ).

Intestinal metaplasia was not detected in any patients of FOBT (+) group but was detected in 7 patients of FOBT (-) group. There was no statistically significant difference between the two groups in terms of the presence of intestinal metaplasia $(\mathrm{p}=0.44)($ Table 1$)$.

Table 1. Analysis of Age, Gender, Hemoglobin, Ferritin, H. pylori, Intestinal Metaplasia

\begin{tabular}{lccl}
\hline \multicolumn{1}{c}{ Variables } & $\begin{array}{c}\text { FOBT }(+) \\
(\mathbf{n = 3 8})\end{array}$ & $\begin{array}{c}\text { FOBT }(-) \\
(\mathbf{n = 3 1 1})\end{array}$ & $\begin{array}{l}\text { P valu } \\
\text { e }\end{array}$ \\
\hline $\begin{array}{l}\text { Age }(\text { mean } \pm \mathrm{s} \\
\text { d) }\end{array}$ & $58.89 \pm 12.89$ & $55.08 \pm 14.99$ & $0.27^{*}$ \\
$\begin{array}{l}\text { Gender } \\
\text { Female }\end{array}$ & & & $0.26^{*}$ \\
Male & 23 & 216 & $*$ \\
$\begin{array}{l}\text { Hemoglobin }(\mathrm{g} \\
\text { /dl) }\end{array}$ & $12.35 \pm 0.78$ & $13.35 \pm 1.84$ & $<0.05$ \\
$\begin{array}{l}\text { Ferritin (mg/L) } \\
\text { H. pylori }\end{array}$ & $59.54 \pm 44.56$ & $80.19 \pm 77.18$ & $* 0.40^{*}$ \\
$\begin{array}{l}\text { Intestinal meta } \\
\text { plasia }\end{array}$ & 3 & 15 & $0.31^{*}$ \\
\hline
\end{tabular}

*: Mann-Whitney U test was used. **: Chi-square test was used. $\mathrm{P}<0.05$ was considered significant.

103 (29.5\%) patients underwent upper GIS endoscopy and $246(70.5 \%)$ did not. The rate of upper GIS endoscopy was $44.7 \%$ in patients with FOBT $(+)(\mathrm{n}=17)$ and $27.6 \%$ in patients with FOBT $(-)(\mathrm{n}=86)$. There was a significant difference between the two groups in terms of the rate of upper gastrointestinal endoscopy $(\mathrm{p}=0.03)$.
Upper GIS endoscopy in FOBT (+) patients revealed antral gastritis in 7 patients, alkaline reflux gastritis in 1, pangastritis and bulbitis in 7, duodenal ulcers in 1 and normal in 1 patient. Upper GIS endoscopy in FOBT (-) patients revealed antral gastritis in 23 patients, alkaline reflux gastritis in 4, pangastritis in 5, esophagitis, pangastritis and bulbitis in 18, pangastritis and bulbitis in 21 , alkaline reflux gastritis in 6, duodenal ulcer in 3 , malignancy in 1 and normal in 1 . There was no significant difference between endoscopic biopsy results between the two groups $(\mathrm{p}=0.11)($ Table 2$)$.

$79(22.6 \%)$ of the patients underwent colonoscopy and $251(77.7 \%)$ were not performed. The rate of colonoscopy was $47.4 \%$ in patients with FOBT $(+)(\mathrm{n}=18)$ and $19.5 \%$ in patients with FOBT $(-)(\mathrm{n}=61)$. There was a significant difference between the two groups in terms of the rate of colonoscopy $(\mathrm{p}<0.001)$.

18 of the patients (47.4\%) with (+) FOBT underwent colonoscopy. Hemorrhoidal disease was detected in 12 patients, neoplastic adenoma in 2 patients and malignancy in 4 patients. 61 of the patients $(\% 19,6)$ with (-) FOBT underwent colonoscopy. Hemorrhoidal disease was found in 23 patients, non-neoplastic adenoma in 4, neoplastic adenoma in 11 , colitis in 8 , malignancy in 1 , diverticulosis in 1 and normal in 13 patients. There was a statistically significant difference between the two groups in terms of disease diagnoses $(p<0.001)$ (Table 3).

Table 2. Comparative pathology results of upper gastrointestinal endoscopy

\begin{tabular}{lcc}
\hline Pathological outcome & FOBT (+) & FOBT (-) \\
\hline Antral gastritis & 7 & 23 \\
Alkaline reflux gastritis & 1 & 10 \\
Pangastritis and bulbitis & 7 & 21 \\
Duodenal ulcers & 1 & 3 \\
Normal & 1 & 5 \\
Pangastritis in 5 & - & 5 \\
Esophagitis, pangastritis & - & 18 \\
and bulbitis & - & \\
Malignancy & $\mathrm{n}=17$ & $\mathrm{n}=86$ \\
Total & $44.7 \%$ & $27.6 \%$ \\
& \multicolumn{2}{c}{$(\mathrm{p}=0.11)$}
\end{tabular}


Table 3. Comparative pathology results of the colonoscopy

\begin{tabular}{lll}
\hline $\begin{array}{l}\text { Pathological } \\
\text { outcome }\end{array}$ & FOBT $(+)$ & FOBT (-) \\
\hline Hemorrhoidal disease & 12 & 23 \\
Neoplastic adenoma & 2 & 11 \\
Malignancy & 4 & 1 \\
Non-neoplastic & - & 4 \\
adenoma & & \\
Colitis & - & 8 \\
Diverticulosis & - & 1 \\
Normal & - & 13 \\
\hline & $18(47,4 \%)$ & $61(19,6 \%)(\mathrm{p}$ \\
& & $<0.001)$ \\
\hline
\end{tabular}

\section{Discussion}

Colorectal cancer is the third most common cancer in men and the second most common cancer in women worldwide (Torre et al., 2012). Due to its slow progression from detectable precancerous lesions, initially symptoms may be nospecific and may be far from being diagnostic and early detection by screening test may be significantly life saver. Screening programs can reduce CRC mortality by $15-30 \%$ (Mandel et al., 2000; Von Karsa et al., 2013; Qaseem et al., 2012). FOBT is available, cheap and noninvasiv test for the CRC screening. The test sensitivity appears to be about 50 ([Lansdorp-Vogelaar et al.,2009). In our study, $22.6 \%$ of patients had colonoscopy. This may be due to the small number of patients with positive FOBT results. In addition, $47.4 \%$ of patients with FOBT positive and $19.6 \%$ of FOBT negative patients too underwent colonoscopy. It is expected to apply colonoscopy which is invasive but diagnostic, more specific and which allows for biopsy in FOBT positive patients. However, colonoscopy was decided even in up to $20 \%$ of patients with negative FOBT too. In this decision, other risk factors for colorectal cancer were taken into consideration by the clinician. To determine the CRC risk ratio, a number of CRC prediction models have been designed and validated in different settings (Williams et al.,2016; Rodriguez-Alonso et al., 2015). Other factors as age, sex and questionnaire-based information were used to make colonoscopy decision beside the FOBT (Joaquin et al., 2017). In our study, the mean age of the patients who underwent colonoscopy with negative FOBT was $54.95 \pm$ and $37(60.7 \%)$ were female and 24 $(39.3 \%)$ were male of these patients. The mean age of the patients, with other risk factors, may have led to the decision of endoscopy.

In our study, 21 patients with positive FOBT refused to undergo upper gastrointestinal endoscopy. It is certain that this will cause a delay in the diagnosis of patients and a decrease in the percentage of possible malignancy diagnosis. Several complex factors play a role in affecting the patient's participation and sustained adherence. Screening rates have not increased as much as desired and remain at approximately $60 \%$ (Sabatino et al.,2015).

Similar and benign diagnoses were detected in upper GIS endoscopy of FOB positive and negative patients. In fact, one malignancy detection is in the FOB negative group. Already, it is known that clinical suspicion is more prominent than FOB in the suspicion of stomach and duodenal cancer. However, as known that atrophic gastritis and intestinal metaplasia are precancerous, early detection of these patients is important in terms of prognosis and mortality (Vannella et al., 2011).

In our study, Helicobacter Pylori (Hp) was detected in some of patients in FOBT (+) and both in FOBT (-). Hp is the causative agent of chronic gastric infections, and it has been estimated that at least half of the world's population is infected. A recent meta-analysis on the global prevalence of $\mathrm{Hp}$ infection has shown an overall prevalence of $44.3 \%$ (Zamani M et al., 2018). Socio-economic status, together with the level of urbanization and sanitation conditions, likely reflects the differences of Hp prevalence from country to country (Hooi et al., 2017). It is involved in the etiology of many gastrointestinal diseases as gastritis, peptic ulcer, functional dyspepsia, stubborn iron deficiency anemia, gastric mucosa-associated lymphoma (maltoma) and gastric adenocarcinoma (Lee et al., 2016; Bae et al., 2018; Adamu et al., 2010). Hp as the main cause of gastritis confined to the antral mucosa and causes duodenal ulcer (Marshall. et al.,1984). Moreover, it has become clear that oxyntic atrophy is essential for gastric cancer (Testoni et al. 1987) including the carcinogenic effect of Hp infection (Uemura $\mathrm{N}$ et al., 2001).

\section{Conclusion}

Colorectal cancer is one of the most common cancers in the world. Therefore, importance should be given to its screening and detection. The FOBT is a useful and simple guide in colorectal cancer screening also in peptic ulcer or gastric cancer which can be followed by chronic bleeding. On the other hand, Hp should be detected and treated because it is accepted precancerous and it causes many benign and malignant diseases of the stomach. We observed that patients were not aware 
of early cancer diagnosis by FOBT follow-up and endoscopy. Patients should be well informed about the FOBT importance about early detection of colorectal malignancy.

Ethics Committee Approval: Ethics committee approval was received for this study from Clinical Research Ethics Committee of Ordu University.

Peer-review: Externally peer-reviewed. Author Contributions: Concept- Ö.Ö., DesignÖ.Ö., Ç.A., H.Ç., Supervision- Ç. A., Literature Review- Ö. Ö., Writing- Ö. Ö., Critical Review- Ö. Ö.

Conflict of Interest: No conflict of interest was declared by the author.

Financial Disclosure: The author declared that this study hasn't received no financial support.

\section{References}

Adamu MA, Weck MN, Gao L, Brenner $\mathrm{H}$. Incidence of chronic atrophic gastritis: systematic review and meta-analysis of followup studies. Eur J Epidemiol. 2010;25:439-448.

Bae SE, Choi KD, Choe J, Kim SO, Na HK, Choi JY et al. The effect of eradication of Helicobacter Pylori on gastric cancer prevention in healthy asymptomatic populations. Helicobacter. 2018;23:e12464

Carroll MR, Seaman HE, Halloran SP. Tests and investigations for colorectal cancer screening. Clin Biochem. 2014;47:921-939.

Eusebi LH, Zagari RM, Bazzoli F. Epidemiology of Helicobacter Pylori infection. Helicobacter. 2014;19 Suppl 1:1-5.

Hooi JKY, Lai WY, Ng WK, Suen MMY, Underwood FE, Tanyingoh D et al. Global Prevalence of Helicobacter Pylori Infection: Systematic Review and Meta Analysis. Gastroenterology. 2017;153(2):420-9. 10.1053/j.gastro.2017.04.022

Ioannou GN, Rockey DC, Bryson CL, Weiss NS. Iron deficiency and gastrointestinal malignancy: a population-based cohort study. Am J Med. 2002;113(4):276-280.
Joaquín Cubiella , Jayne Digby, Lorena RodríguezAlonso, Pablo Vega, María Salve, Marta DíazOndina et al. The fecal hemoglobin concentration, age and sex test score: Development and external validation of a simple prediction tool for colorectal cancer detection in symptomatic patients, Int. J. Cancer:140, 22012211 (2017)VC2017 UICC

Lansdorp-Vogelaar I, van Ballegooijen M, Boer R, Zauber A, Habbema JD. A novel hypothesis on the sensitivity of the fecal occult blood test: Results of a joint analysis of 3 randomized controlled trials. Cancer. 2009;115:2410-2419.

Lee YC, Chiang TH, Chou CK, Tu YK, Liao WC, Wu MS et al. Association Between Helicobacter Pylori Eradication and Gastric Cancer Incidence: A Systematic Review and Metaanalysis. Gastroenterology. 2016;150:11131124.e5

Mandel JS, Church TR, Bond JH, Ederer F, Geisser MS, Mongin SJ, et al. The effect of fecal occultblood screening on the incidence of colorectal cancer. New Engl J Med. 2000;343(22):16031607.

Marshall B.J., Warren J.R. Unidentified curved bacilli in the stomach of patients with gastritis and peptic ulceration. Lancet. 1984;1:13111315. doi: 10.1016/S0140-6736(84)91816-6.

Qaseem A, Denberg TD, Hopkins RH Jr, Humphrey LL, Levine J, Sweet DE et al. Screening for colorectal cancer: a guidance statement from the American College of Physicians. Ann Int Med. 2012;156(5):378-386.

Rodríguez-Alonso L, Rodríguez-Moranta F, RuizCerulla A, Lobatón T, Arajol C, Binefa G et al. An urgent referral strategy for symptomatic patients with suspected colorectal cancer based on a quantitative immunochemical faecal occult blood test. Dig Liver Dis 2015;47:797-804.

Sabatino SA, White MC, Thompson TD, Klabunde $\mathrm{CN}$; Centers for Disease Control and Prevention (CDC) Cancer screening test use - United States, 2013. MMWR Morb Mortal Wkly Rep. 2015;64:464-468.

Testoni P.A., Masci E., Marchi R., Guslandi M., Ronchi G., Tittobello A. Gastric cancer in chronic atrophic gastritis. Associated gastric ulcer adds no further risk. J. Clin. Gastroenterol. 1987;9:298-302. doi: 10.1097/00004836198706000-00011.

Torre LA, Bray F, Siegel RL, Ferlay J, LortetTieulent J, Jemal A. Global cancer statistics, 2012. CA Cancer J Clin. 2015;65:87-108. 
Uemura N., Okamoto S., Yamamoto S., Matsumura N., Yamaguchi S., Yamakido M. Et al. Helicobacter Pylori infection and the development of gastric cancer. N. Engl. J. Med. 2001;345:784-789.

doi: 10.1056/NEJMoa001999.

Vannella L, Lahner E, Bordi C, Pilozzi E, Di Giulio E, Corleto VD et al. Reversal of atrophic body gastritis after $H$. pylori eradication at long-term follow-up. Dig Liver Dis. 2011;43:295-299.

Von Karsa L, Patnick J, Segnan N, Atkin W, Halloran S, Lansdorp-Vogelaar I, et al. European Colorectal Cancer Screening Guidelines Working Group, European guidelines for quality assurance in colorectal cancer screening and diagnosis: overview and introduction to the full supplement publication. Endoscopy. 2013;45(1):51-59.

Williams TGS, Cubiella J, Griffin SJ, Walter FM, Usher-Smith JA. Risk prediction models for colorectal cancer in people with symptoms: a systematic review. BMC Gastroenterol. 2016;16:63.

Zamani M, Ebrahimtabar F, Zamani V, Miller WH, Alizadeh-Navaei R, Shokri-Shirvani J et al. : Systematic review with meta-analysis: the worldwide prevalence of Helicobacter Pylori infection. Aliment Pharmacol

Ther. 2018;47(7):868-76. 10.1111/apt.14561 